this, but if we could obtain a really accurate report of the chronicity of the cases, the number of sinuses affected, the surgical method employed in operating, the treatment of the wound and the results obtained as regards cure, relapse, the amount of disfigurement produced and a fatal issue, we would possess a valuable guide for our future work. The statistics which I have quoted here are of a somewhat fragmentary nature and are gathered from the work of a comparatively small number of men. Perhaps the time is not far distant when we may be the fortunate possessors of the information to which I refer. It should be the aim of all of us to so perfect our methods that we are able to operate on every patient with frontal sinus suppuration, confident that we will effect a cure with the minimum of disfigurement.

In conclusion I wish to acknowledge the valuable assistance which I have received from my friend, Mr. John Grieve, in the preparation of a number of my photographs, and to express my thanks to Prof. D. J. Cunningham of the University of Edinburgh for the opportunity kindly afforded me for dissection on the cadaver.

\section{DEMENTIA PRAECOX.*}

\section{F. X. DERCUM, M.D.}

Professor of Nervous and Mental Diseases. Jefferson Medical College; Neurologist to the Philadelphia Hospital. PHLADELPHIA.

In the writings of some of the earlier authors, notably Pinel, Spurzheim and Esquirol, we find that they recognized the affection now so widely known as dementia præcox. This recognition was, to be sure, vague and imperfect; the affection was naturally confounded with other dementias, paretic, organic and alcoholic and yet these early writers were aware that there was a form of idiocy which was not congenital, and which supervened only after the organism had attained a certain degree of development. Spurzheim, for instance, speaks of an "accidental idiocy" while Esquirol speaks of "accidental and acquired" idiocy; thus the latter says that there are children who are very well at birth, who increase in stature at the same time that their intelligence develops and who are very sensitive, lively, irritable, pass onate and possessed of a brilliant imagination, a developed intelligence and an active spirit. This activity, not being in relation to the physical strength, these creatures use themselves up, they rapidly exhaust themselves, the intelligence becomes stationary. they acquire nothing more, the hopes to which have given rise vanish, while they finally pass into a terminal period of dementia. Subsequent writers recognized similar conditions, e. g., Rousseau and Moreau, though the former regarded primary dementia of the period of puberty as very rare, while the latter declares that such cases (early mental maturity and later idjocy) are very frequent. Morel. ${ }^{1}$ under the title of "Hereditary Insanity, with Limited Intellectual Existence, Tendencies, Precocious and Innate to Disease, Transition to Idiotism, the most Irremediable, under the Influence of Certain Intercurrent Causes, etc.," describes cases which clearly belong to the hebephrenic or simple form of dementia præcox, and in commenting upon them, he says that a sudden immobilization of all of the faculties, une démence précoce, indicates that the

- Read in the Section on Nervous and Mental Diseases of the American Medical Assoclation. at the Fifty-fifth Annual Session. June, 2904

1. Traite de Maladies Mentales, pp. 562 to 566 . young subjects have reached the termination of the intellectual lives of which they are capable. They live intellectually only up to a certain age, after which arrest takes place and they fall progressively into a state which he can only compare to idiocy. To Morel belongs the credit of having first made use of the expressive designation démence précoce, and it was Arnold Pick of Prague who first employed its Latin equivalent, dementia pracox, now so largely used. Pick described a number of cases clearly belonging to this group of affections.

It is not necessary to dwell here on the epoch-making studies of Kahlbaum, who first differentiated hebephrenia and catatonia $(1863,1874)$ from the great mass of demented cases, nor is it necessary to speak of Hecker's historical study of hebephrenia (1877). Time and the object of this paper also forbid comment on the writings of subsequent authors.

There is one author, however, whose name must be mentioned, for he has made the domain of dementia præcox peculiarly his own. His views, novel and striking, at one and the same time excite our admiration and challenge our criticism. It was Kraepelin who first gave to the term dementia precox a broad interpretation. His point of view appears to have been reached by a process of gradual development. In the fifth edition of his Psychiatry, he still makes use of the term dementia præcox as designating a form of mental disease practically the equivalent of the hebephrenia of Hecker and Kahlbaum, and he limits the term to this designation. In this edition (the fifth) catatonia is still treated separately and not embraced under the heading of dementia præcox, and the like treatment is accorded to dementia paranoides. In the sixth edition, however, of his work, Kraepelin greatly expands the term dementia præcox; in fact, he gives it a new meaning. He no longer describes a specific form under this name, but applies it equally to hebephrenia, catatonia and dementia paranoides ; in other words, these diseases are now treated by him as only so many different forms of one affection. It is difficult to speak in moderate terms of the value and importance of this brilliant generalization. It has served to greatly reduce the difficulty of study and classification, and even of prognosis. Furthermore, it has enabled us to give to certain symptoms a fundamental value and to others a value merely secondary-in other words, to properly co-ordinate related facts.

However, this change, and the present status of the subject, makes it imperative that certain important points should be considered. To begin, the name itself, dementia præcox, demands discussion. The term "dementia" implies of necessity a downward or degenerative process; in the psychiatric mind it is associated with the mass of hopeless terminal demented states which are met with in the asylums, and yet, as a matter of fact, it is known that a history of persistent or permanent mental loss by no means alwavs obtains in dementia præcox. Every asvlum will bear witness to the fact that cases of hebephrenia and catatonia do recover, while even a larger percentage of recoveries (among hebenhrenies) is noted among the milder cases, whose condition does not demand asylum commitment, i. e., the extra-mural cases. While it is true that in the great majority a hopeless dementia is the final outcome, still Kraepelin himself admits a not small percentage of recoveries, 8 per cent. for hebephrenics and as high as 20 per cent. for cata- 
tonics-though he considers the possibility of recurrences.

If recovery takes place at all in dementia præcox, surely the term dementia is inappropriate; the objection to its use is not only scientific but ethical. Far better is it to employ a term such as das Jugendirresein of German writers, ${ }^{2}$ a term the English equivalent of which is the insanity of youth, or better still, the insanity of adolescence. The term dementia præcox conveys, in its very sound, an unfavorable prognosis; not so with the term insanity of adolescence. This presupposes nothing as regards the future, and leaves the question of recovery to be determined by the course of the case; sentence is not pronounced on the patient at the time of the making of the diagnosis, but is charitably as well as scientifically withheld. Finally, the fact that youthful patients are also liable to suffer from the various infectious or toxic psychoses and to manic-depressive insanity can offer no objection to confining the term insanity of adolescence to the field occupied by hebephrenia, catatonia and dementia paranoides. Neither the infectious and toxic insanities nor the manic-depressive form are peculiar to youth. Further they already have distinguishing appellations.

Another point of importance is the use of the term hebephrenia. Hebephrenia implies of necessity a disease of puberty, and while there can be no doubt that the time at, near or about this epoch is the most favorable period for the development of this affection, it is requally well established that hebephrenia may occur much later. Furthermore, the term hebephrenia is apt to convey to the mind of the student that there are special and distinguishing features presented by its history and symptoms, whereas it is in reality the simple expression of dementia præcox, and it should be so designated. It is certainly far less confusing to the mind of the student to speak of the simple form of dementia præcox or insanity of adolescence than to speak of hebephrenia. In fact, J. Rogues de Fursac, one of the French disciples of Kraepelin, has already adopted this term. Instead, therefore, of speaking of the different forms of dementia præcox as hebephrenia, catatonia and dementia paranoides, we would merely speak of the simple form, the catatonic form and the paranoid form. Terminology is often confusing, and whenever possible clearness should be aimed at.

Holding now clearly before our minds these three forms, let us briefly analyze their elements. In reading Hecker's historical paper on hebephrenia, one gleans three essential symptoms; first, an initial period of variable duration during which the patient is in a phase of depression; second, a period during which the depression fades and elements of expansion become manifest; third, and most important of all, a progressive dementia noticeable early and becoming gradually more and more marked; this is a clinical description which $\mathrm{I}$ need hardly point out accords closely with our experiences of to-day.

If we subject the symptom group of catatonia to a similar process of analysis, we find that there are present, as in hebephrenia, the same cardinal factors- the initial wave of depression, the subsequent wave of expansion. or mingled expansion and denression, and a progressive dementia, together with definite and characteristic motor symptoms which give to the disease its specific peculiarities and name, $i$. e., the fixed attitudes, the stereotypy, catatonia, automatism, automatic

2. Troemner and Ilberg. resistance, etc. When we turn our attention to dementia paranoides, and I now use the term in Kraepelin's original application-as employed in his fifth editionwe come to a group of cases in whom there is as before an initial wave of depression, a subsequent wave of expansion and progressive dementia, but added to which there are not now special motor phenomena, but special psychic phenomena in the shape of delusions, persecutory or expansive, which in their character-though unsystematized-suggest or simulate paranoia.

In studying the group of insanities of adolescence as a whole, certain other facts also become evident; first we learn, as was pointed out several years ago by Pickett, that the various forms tend to occur by preference at certain ages; that is, other things equal, cases of hebephrenia begin at a younger average age than do cases of catatonia; second, cases of catatonia begin at an earlier average age than cases of dementia paranoides, and thirdly, cases of dementia paranoides constitute the oldest group of all. That this generalization is not detailed in its application goes without saying. It is as are other scientific truths, general in its character, but is of the most decided significance. To some extent, the phenomena observed are in keeping with the facts of age, that is, the symptoms largely correspond to the degree of mental development to which the patient has attained at the time of the inception of the disease.

In the early, the hebephrenic or simple form, we have a wave of depression and a wave of exaltation, which is usually of a moderate altitude. It is unusual for the emotional wave to assume the depth or height seen in older cases. Sometimes, indeed, the depression and expansion are so slight that they are described by such terms as "mild depression," "mild hypochondriasis" or are merely characterized by a neurasthenoid group of symptoms. Indeed, the wave of expansion or exaltation may be so mild that its manifestations may be revealed only by physical elation, or boisterous and noisy conduct.

Again in hebephrenia the delusive beliefs are manifold and without attempt at definite arrangement; in other words, there are present the symptoms of moderate initial depression, moderate expansion with a simple dementia. When we turn our attention to catatonia we find that the phases of depression and expansion are somewhat more marked, while the psychic content of the delusions is somewhat higher-less childish or puerile on the whole-than in hebephrenia and a tendency to some arrangement of ideas, however loose, is frequently observed. In dementia paranoides, phases of depression and expansion are likewise marked, though the most prominent features now present are the delusions and hallucinations which both in their content and persistence suggest paranoia.

Let us now consider briefly the position of dementia paranoides. In his fifth edition, Kraenelin, to whom we owe this term, limits it to cases characterized by disconnected persecutory and expansive ideas, which rapidly pass into a persistent terminal confusion or dementia. In his sixth edition he made a decided change; this consisted in including under dementia paranoides the group of cases which he had formerly designated as the "phantastic form" of paranoia. The change was a very radical one, for it disposed at one blow of a large mass of cases universally regarded as belonging to paranoia. It includes almost the totality of the délires systemtematisés of French writers-the delire chronique 
of Magnan-and leaves nothing of paranoia proper except the form corresponding to Magnan's "insanity of the degenerates," or Kraepelin's "combinirte Form." In his fifth edition, Kraepelin depicted as phantastic paranoia, the form in which the delusions gradually withdraw themselves from the influence of actual perceptions, and are based more and more on hallucinations and independent invention; the disease presents the usual phases of depression, transformation and expansion. In his seventh edition, Kraepelin adheres to this radical substitution.

I can not but feel that this change has been an unfortunate one, and that by it Kraepelin does violence to facts. It is certainly absurd to speak of a dementia as precocious which may begin as late as $40,45,50$ or 55 years of age. Equally inapplicable is the term "Jugendirresein." In concluding his very excellent description of this form of paranoia in his fifth edition ${ }^{3}$, Kraepelin says that the majority of the cases occur between 25 and 40 years of age; he adds that there are a group of cases which begin at a more advanced agebetween the fiftieth and sixty-fifth year. In his description of the phantastic form of paranoia, in the sixth and seventh editions of his work, included now under dementia paranoides, this paragraph as to age is omitted. Why? Are the facts which were true in 1896 no longer true in 1899 or 1904 ? That they are still true will be admitted by every physician of asylum experience. Do such facts warrant the forcing of this group of cases into the frame of precocious dementia? That this group of cases really belongs under the head of paranoia we believe is established by the following: In the first place, it is impossible to sharply differentiate them from those to which Kraepelin has now limited the term-a group which, as we have already stated, corresponds to that designated at one time by Magnan as the insanity of the degenerate, and which was formerly designated by Kraepelin as the "combinirte Form." The latter constitute a group which is characterized by a very slow evolution of symptoms and by a very prolonged course, but in which the stages of depression, transformation and expansion are alike discernible. The cases are characterized by the fact that their delusions are based more or less largely on misinterpreted perceptions rather than on hallucinations, and that the delusions are perhaps better defined, better systematized and more firmly fixed than in the "phantastic form" or délire chronique, and yet these differences are only relative. They are, after all, only variations of degree and not of kind. Even if we take the point in regard to the absence of hallucinations in the "combinirte Form" as the standard of differentiation, we find that the moment we analyze it, it breaks down. Not only is it a fact that special sense hallucinations-hallucinations of hearing and of sight-do occur in some cases of this form, but my own observation has convinced me that while special sense hallucinations are relatively uncommon, general coenesthetic and psycho-motor hallucinations are by no means infrequent, and that the latter, as in the other forms of paranoia, form the foundation stone on which is based the mental attitude and the emotional tone of the patient. To define paranoia as a disease of the logical apparatus is a bizarre misstatement, which leaves out the intrinsic and fundamental features of the affection. That there is in all probability an underlying unity in all of the auto-degenerative psychoses which binds together all of the various forms

3. Page 697 . of mental disease beginning with hebephrenia and ending in Magnan's paranoia (insanity of the degenerate, "combinirte F'orm") is very probable. Perhaps there is an underlying unity of cause; indeed, it seems to me that this is probable. The mental picture presented is so varied by the elements of age and other factors that special clinical pictures are inevitable. If a term be devised (dementia præcox being abandoned) which would include all of these progressive degenerative changes under one head it would perhaps be right to consider them together and to treat of them as one disease. In such case, there would not only be included the phantastic paranoia, but the other form of the paranoia as well. I believe, however, that such a generalization as this would be scientifically and practically very disadvantageous, and would be as objectionable as is the present inclusion of the phantastic form of paranoia under dementia præcox.

We have in the solar spectrum seven colors, each color passing by a most gradual transition into another. Shall we, because it is impossible to draw hard and fast lines-because we can not say, for instance, where violet ends and blue begins, say that violet and blue are the same; or that green and yellow-most opposite in their reaction on the human sensorium-are the same because they pass by insensible transition one into the other? Surely nothing can be gained by wiping out well estąblished lines of demarcation. Change does not always mean progress; it sometimes means error. Practical experience teaches us that no sharp differentiation can be drawn between the various forms of dementia præcox-hebephrenia, catatonia and dementia paranoides. Every now and then we meet with cases of hebephrenia in which passing motor phenomena, convulsions, transitory rigidity or stereotypy is noted, or again cases of dementia paranoides in which like features cause an approximation to catatonia. Similarly I believe that it is often difficult, if not impossible, to draw a differentiation between a dementia paranoides and a phantastic paranoia just as it is impossible always to make an absolute differentiation between the latter and the paranoia of Magnan, the "combinirte" form of Kraepelin.

\section{DISCUSSION.}

DR. F. W. LANGdoN, Cincinnati, said that dementia præcox as a name, apparently, does not apply to a considerable number of these cases. When this condition develops at 30 or 40 , or even at 50 years of age, and when it is not terminal dementia nor paretic dementia, nor post-organic dementia, they are classed as dementia præcox. If it can be shown that some of these patients had their original attack at adolescence and that what was looked on as a recovery has really been only a remission, then perhaps they are correctly called dementia pracox. Dr. Langdon considers that this condition is primary degenerative psychosis, which may be arrested for a time at various periods, and which, in most cases, eventually tends toward complete dementia. While no sharp lines of demarcation can be drawn in the psychoses, yet there must be some kind of demarcation for practical purposes, just as in the colors of the spectrum artificial lines must be drawn where the natural do not exist. Dr. Isangdon thinks that while the term insanity of adolescence may be applicable to cases of dementia prxcox, it does not clear up matters very much, because cases occur at 30,40 , or at 50 years of age, which can not be called insanity of adolescence unless it can be shown that they began at an earlier age. Experience seems to attach a significance to the term dementia pracox, though probably there is no reason why primary or idiopathic dementia would not be just as suitable.

Dr. F. X. Dercum stated that he believes that the older 
cases should not be classified with the younger ones. He believes that the original designation ought to stand and to stand unmodified; otherwise it loses a great deal of its clinical value. He does not believe that we ought to wipe out distinctions where they exist, just because the cases merge one into the other. The early cases are a distinct group by themselves; they are different from the adult cases of paranoia. It seems to him that it mars the picture, and certainly makes the term meaningless to include the adult cases of paranoia with those of dementia præcox. He thinks that it would be better to classify the juvenile cases under the term insanity of adolescence and leave off the term dementia præcox.

\section{THE NATURE OF TRAUMATIC SCLEROSIS.* ARTHUR CONKLIN BRUSH, M.D.}

Neurologist to the Kings County, Brooklyn Fye and Far, Williams burg Hospitals, Home of St. Giles and Bushwick and East Brooklyn Dispensary.

BROOKLYN, NEW YORK CITY.

Though most of the confusion which once surrounded the results of trauma to the nervous system has been dispelled, so that we are able to recognize definitely most of the functional and organic diseases for which trauma is a competent producing cause, the nature of the condition in question is still open to investigation. The questions at issue at the present time seem to be, is this pathologic entity with an organic basis, is it only a grave type of hystero-neurasthenia, is it a distinct functional neurosis, or is it a type of true multiple sclerosis?

The evidence on which rests the claim for an organic basis for this condition dates back to the findings of Westphal, who, in 1878, described disseminated foci of sclerosis in the cerebrospinal axis as a result of trauma. Bramwell also described these lesions as secondary to minute hemorrhages. Sterling Kranthal, Dumenil, Petit and Edges confirmed these findings in their descriptions of degenerations of the columns of the cord, minute hemorrhages into its gray matter, and arterial sclerosis of both spinal and cerebral arteries as a result of trauma.

The evidence furnished by these pathologic findings is further supported by the results furnished by the experiments of Mendal, who fastened dogs to a rapidly revolving table and thus produced adhesions of the cerebral membranes, increase in the glia nuclei, vascular congestion and degenerative cell changes. Fustener, by continuing the experiment for a greater time, was able to produce besides these changes sclerosis of the posterior columns and optic nerves. Schmaus, by diffuse violence applied to the spine, was able to produce degencrations in the spinal neurons and vascular degenerations. His conclusions, as summed up by Knapp, are: that there is a distinct traumatic necrosis of nerve fibers: that more fibers die than can be recognized; that the fibers may be merely fatigued (fatal cases with no lesions and recoverable ones); that this fatigue of fibers may cause their death (gradually produced lesions), and that a gliosis ending in tumor formation mav oreur.

Since the time of these writers their findings have been so often confirmed that there seems to be no conflict of evidence as to the theory that trauma is a competent producing cause for these findings.

Our present knowledge of the results of diffuse vio-

* Read in the Section on Nerrous and Mental Diseases of the Amerlcan Medical Association, at the Fifty-fifth Anntual Session, June, 1904 lence to the cerebrospinal axis can be summed up as follows: That said violence can produce a condition known as concussion or commotion; that in this con ri. tion there may be localized hemorrhages, laccration:

contusion of nerve tissue, multiple minute hemorrliags or thrombi scattered throughout the cerebrospinal axis, general edema, distension and infiltration of the blood vessels; that from these lesions the following secondary changes may occur: The vascular hyperemia and infiltration of the vessel walls not only decreases the amount of nutrient lymph supplied to the nerve tissue, but also interferes with its return by a proliferation of the adrentitia and a collection of débris and leucocytes in the perivascular spaces.

This then deprives the nerve cells of nutriment, and at the same time they are poisoned by waste products. Monti's observations show that the nerve cells die in a few hours when their nutrition is entirely cut off, and that defective nutrition causes the same changes after longer periods; the degenerative changes beginning in the distal parts of the cell and finally destroying the nucleus.

The effect of rupture of an axion is to cause swclling of its cell body, an eccentric position of nucleus, a disappearance of the chromaphilic elements, a loss of the striped appearance, and finally disintegration. In embolism and thrombosis the cells in the affected areas become edematous, the chromatin particles collect in the centers and finally disintegration occurs. In all forms of injury to the nerve cells its dendrites are first to degenerate, then its axon, and finally the cell body. The changes shown in the nucleus of these cells are a more deeply staining of the nucleus, which becomes vacuolated and finally small and angular. Coarse, granular changes are said to be characteristic of the chronic forms of degeneration, and depigmentation of sclerotic processes. The changes described in the neuroglia cells consist of swelling, an engorgement with granular detritis, and finally disintegration. The spider cells are said to resist the longest. There seems to be no conflict of evidence as to the theory that a nerve cell which has undergone degeneration is ever replaced, but we seem to have as yet no facts to show how far this process can be developed so as to forbid recovery.

The final results then of commotion or concussion of the cerebrospinal axis, in which the damage has been severe enough to forbid recovery would appear to be the production of areas of degeneration, areas of sclerosis and possibly arteriosclerosis, Bailey and Meyer considering the latter finding to be a coincidence.

Five cases of my own. which illustrate the various stages of the development of these lesions, have come to autopsy.

CASE 1.-This case. showing the primary lesions, was that of a woman, aged 49, seen in the Kings County Hospital. Iamily and previous personal history, negative.

History.-Two weeks before admission she fell down a flight of stairs, received bruises about the body and limbs, and for a few hours suffered from shock. After one week she became unable to work.

Examination.-Examination showed the patient to be very stout and to lie with the limbs flexed. When made to stand, she slowly sank to the floor. Her speech was indistinct, and she would laugh or cry without obvious cause; memory and volition were poor. There was an intention tremor of the face and limbs, with loss of muscular power. The deep reflexes were exaggerated; anesthesia with ill-defined outline existed below the ellows and knees. The pupils were dilated, but responsive. 